\author{
OAK RIDGE \\ NATIONAL LABORATORY \\ MANAGED BY UT-BATTELLE \\ FOR THE DEPARTMENT OF ENERGY
}

\title{
Comparing Life-Cycle Costs of ESPCs and Appropriations-Funded Energy Projects: An Update to the 2002 Report
}

\author{
John Shonder, Patrick Hughes, and Erica Atkin
}




\section{DOCUMENT AVAILABILITY}

Reports produced after January 1, 1996, are generally available free via the U.S. Department of Energy (DOE) Information Bridge:

Web site: http://www.osti.gov/bridge

Reports produced before January 1, 1996, may be purchased by members of the public from the following source:

National Technical Information Service

5285 Port Royal Road

Springfield, VA 22161

Telephone: 703-605-6000 (1-800-553-6847)

TDD: 703-487-4639

Fax: 703-605-6900

E-mail: info@ntis.fedworld.gov

Web site: http://www.ntis.gov/support/ordernowabout.htm

Reports are available to DOE employees, DOE contractors, Energy Technology Data Exchange (ETDE) representatives, and International Nuclear Information System (INIS) representatives from the following source:

Office of Scientific and Technical Information

P.O. Box 62

Oak Ridge, TN 37831

Telephone: 865-576-8401

Fax: 865-576-5728

E-mail: reports@adonis.osti.gov

Web site: http://www.osti.gov/contact.html

This report was prepared as an account of work sponsored by an agency of the United States Government. Neither the United States government nor any agency thereof, nor any of their employees, makes any warranty, express or implied, or assumes any legal liability or responsibility for the accuracy, completeness, or usefulness of any information, apparatus, product, or process disclosed, or represents that its use would not infringe privately owned rights. Reference herein to any specific commercial product, process, or service by trade name, trademark, manufacturer, or otherwise, does not necessarily constitute or imply its endorsement, recommendation, or favoring by the United States Government or any agency thereof. The views and opinions of authors expressed herein do not necessarily state or reflect those of the United States Government or any agency thereof. 
Engineering Science and Technology Division

\title{
2006 Follow-Up on ESPC and Appropriations - Comparing Life-Cycle Costs
}

\author{
John Shonder, Patrick Hughes, and Erica Atkin
}

Oak Ridge National Laboratory

September 2006

Prepared by

Oak Ridge National Laboratory

P.O. Box 2008, Oak Ridge, Tennessee 37831-6285,

managed by UT-Battelle, LLC

for the

U.S. Department Of Energy under contract DE-AC05-00OR22725 



\section{Contents}

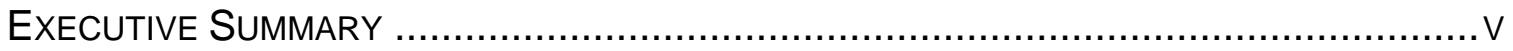

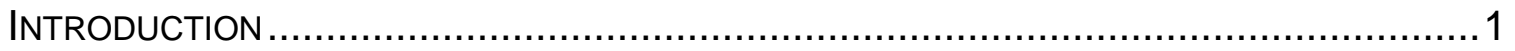

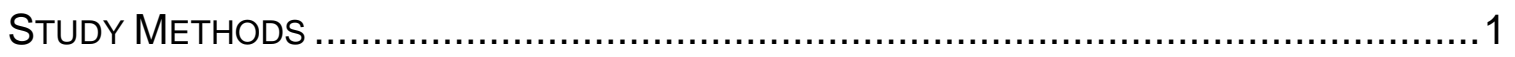

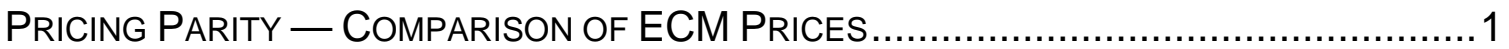

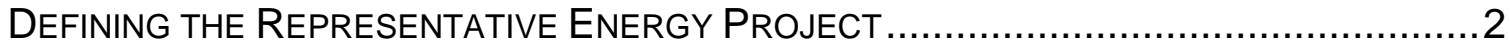

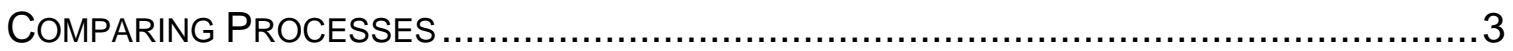

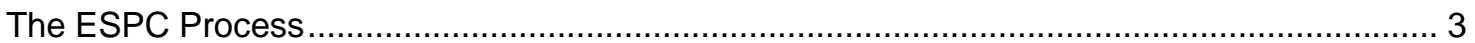

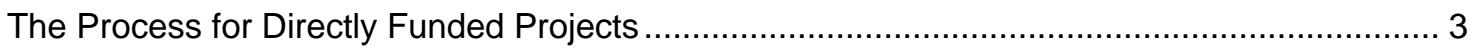

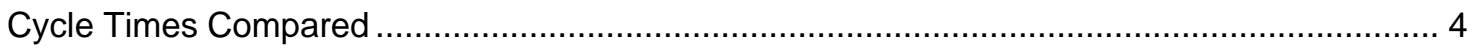

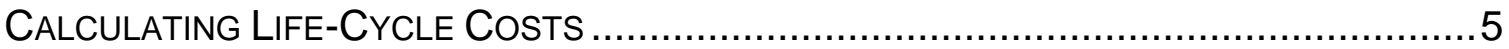

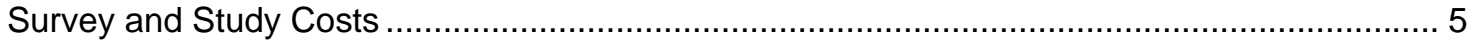

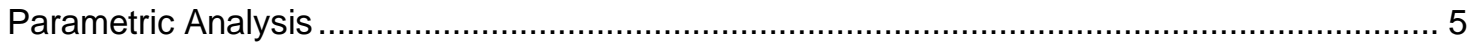

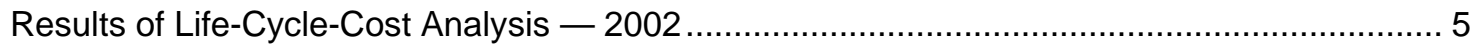

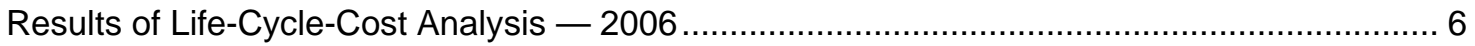

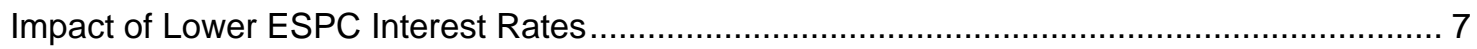

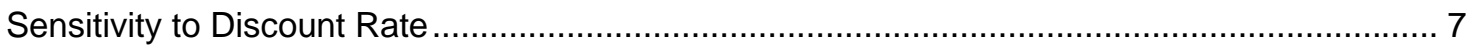

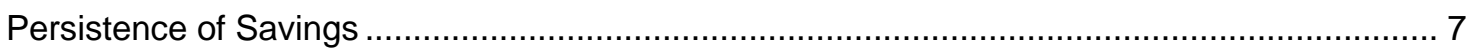

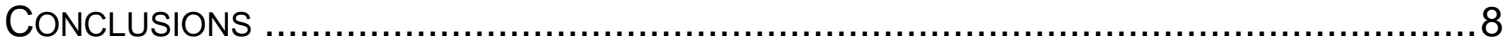




\section{Executive Summary}

A study was sponsored by FEMP in 2001 - 2002 to develop methods to compare life-cycle costs of federal energy conservation projects carried out through energy savings performance contracts (ESPCs) and projects that are directly funded by appropriations. The study described in this report follows up on the original work, taking advantage of new pricing data on equipment and on \$500 million worth of Super ESPC projects awarded since the end of FY 2001.

\section{Study Methods}

The methods developed to compare life-cycle costs of ESPCs and directly funded energy projects are based on the following tasks.

- Verify the parity of equipment prices in ESPC vs. directly funded projects

- Develop a representative energy conservation project

- Determine representative cycle times for both ESPCs and appropriations-funded projects

- Model the representative energy project implemented through an ESPC and through appropriations funding

- Calculate the life-cycle costs for each project

\section{Pricing Parity - Comparison of ECM Prices}

The 2002 analysis was based on about $\$ 13$ million worth of chiller replacements, lighting retrofits, and variable-frequency drives. For the 2006 follow-up, the analysis included groundsource heat pumps, chiller replacements, and lighting retrofits, which account for about $40 \%$ of all Super ESPC investment. All prices were adjusted for location and general price inflation and then compared with the growing data base on ECMs implemented in the Super ESPCs. No statistically significant differences were found between ECM pricing for ESPC and directly funded projects.

\section{Comparing Life-Cycle Costs}

The "representative energy project" used as the basis for comparison was defined as the average project implemented under the DOE Super ESPC program. The sample for the 2006 follow-up consisted of all 142 Super ESPC projects awarded through July of 2006, worth \$743 million in project investment, and accounting for about 40 percent of all federal ESPC investment.

All costs entailed in the representative ESPC and appropriations-funded projects are considered in calculating the 20-year life-cycle costs of each.

The primary factors in comparing life-cycle costs of directly funded projects and ESPCs are (1) how much it costs sites to develop funding requests, and (2) how long it takes agencies to deliver appropriated funds to sites. To reflect the range of survey and study costs and cycle times that agencies might experience with their appropriations-funded projects, the 2002 study and this follow-up calculated the life-cycle costs for cycle times ranging from 28 to 74 months and survey and study costs ranging from 4 to $26 \%$ of project cost. Then we calculated the ratios of directly funded project life-cycle costs (for each parameterized case) to the life-cycle costs of the representative ESPC project. 


\section{Impact of Lower ESPC Interest Rates}

For the 2006 follow-up, instead of using the average interest rates for all Super ESPC awards (as we did for the original study), we used the average of rates from the awards since the new requirements for competition and transparency in financing were incorporated into the Super ESPC contracts in 2004. The premiums in the financing on Super ESPCs have dropped by about $50 \%$ since the financing reforms took effect, and lower interest rates have reduced the total payments over contract term for an average Super ESPC project by $16 \%$.

\section{Results of Life-Cycle-Cost Analysis}

Given the average of all awarded Super ESPC projects, along with post-reform financing, ESPCs have a lower life-cycle cost whenever directly funded projects take more than two years longer than ESPCs to complete and survey and study costs are greater than $6 \%$ of project cost. These calculations were done assuming the present discount rate and general inflation rate.

Calculations of compared life-cycle costs are sensitive to the discount rate used in figuring net present value, but higher discount rates improve the comparative value of ESPCs. Since the discount rate is relatively low at this writing, the two-year and 6\% break-even metric stated above is likely conservative.

The results of the 2006 analyses assume that persistence of savings is the same in directly funded projects as it is in ESPCs. Savings guarantees and required annual M\&V ensure that savings do persist in ESPC projects, but such assurances are rare in directly funded projects. Even a small degradation in savings of $0.5 \%$ per year (10\% over 20 years) makes ESPCs more life-cycle costeffective under most realistic circumstances. 


\section{Introduction}

A study was sponsored by FEMP in 2001 - 2002 to develop methods to compare life-cycle costs of federal energy conservation projects carried out through energy savings performance contracts (ESPCs) and projects that are directly funded by appropriations. That study was performed by Oak Ridge National Laboratory and documented in the report, Evaluation of Federal Energy Savings Performance Contracting-Methodology for Comparing Processes and Costs of ESPC and Appropriations-Funded Energy Projects. ${ }^{1}$ The study described in this report follows up on the original work, taking advantage of new pricing data on equipment and on \$500 million worth of Super ESPC projects awarded since the end of FY 2001.

This study uses quantitative analyses to address questions about whether pricing in ESPCs, which are negotiated for best value, is as favorable as prices obtained through competitive sourcing, and whether ESPC as a means of implementing energy conservation projects is as life-cycle costeffective as the standard practice of funding these projects through appropriations.

ESPCs are by definition cost-effective because of their "pay-from-savings" requirement and guarantee, but do their interest costs and negotiated pricing extract an unreasonably high price? Appropriations seem to be the least-cost option, because the U.S. Treasury can borrow money at lower interest rates than the private sector, but appropriations for energy projects are scarce. What are the costs associated with requesting funding and waiting for appropriations? And how is the value of an energy project affected if savings that are not guaranteed do not last?

The objective of the original study was to develop and demonstrate methods to help federal energy managers take some of the guesswork out of obtaining best value from spending on building retrofit energy improvements. We developed a method for comparing all-inclusive prices of energy conservation measures (ECMs) implemented using appropriated funds and through ESPCs. This method illustrates how agencies can use their own appropriations-funded project experience to ensure fair ESPC pricing. The second method, for comparing life-cycle costs, illustrates how agencies can use their experience, and their judgment concerning their prospects for appropriations, to decide whether to finance or wait.

\section{Study Methods}

The methods developed to compare life-cycle costs of ESPCs and directly funded energy projects are based on the following tasks.

- Verify the parity of equipment prices in ESPC vs. directly funded projects

- Develop a representative energy conservation project

- Determine representative cycle times for both ESPCs and appropriations-funded projects

- Model the representative energy project implemented through an ESPC and through appropriations funding

- Calculate the life-cycle costs for each project

\section{Pricing Parity - Comparison of ECM Prices}

The first methodology compares the all-inclusive prices for ECMs implemented through ESPCs and through appropriations-funded projects. All-inclusive ECM prices are a much better indicator of value in pricing than intermediate accounting conventions such as mark-up. We have yet to see

\footnotetext{
${ }^{1}$ Hughes, P. J., J. A. Shonder, T. Sharp, and M. Madgett, 2003. Oak Ridge National Laboratory Report ORNL/TM-2002/150. Available on line at www.ornl.gov/sci/femp/pdfs/espc_lcc.pdf.
} 
any evidence that there is any difference in pricing.

We concentrated the 2002 analysis on about \$13 million worth of three ECMs that are common in Super ESPC and appropriations-funded projects: chiller replacements, lighting retrofits, and variable-frequency drives.

For the 2006 follow-up, additional samples of directly funded ECMs were obtained and a new ECM was considered. This time the analysis included ground-source heat pumps, chiller replacements, and lighting retrofits, which account for about $40 \%$ of all Super ESPC investment.

All prices were adjusted for location and general price inflation and then compared with the growing data base on ECMs implemented in the Super ESPCs. Again, no statistically significant differences were found between ECM pricing for ESPC and directly funded projects. (See figures 1, 2 , and 3 . The axes are unlabeled to preserve the value of the data for use in determining price reasonableness of future project proposals in a streamlined fashion.)

\section{Defining the Representative Energy Project}

The methodology for comparing the life-cycle costs of using ESPCs and appropriations begins with defining a "representative energy project."

The representative project was defined as the average project implemented under the DOE Super ESPC program in terms of

- implementation price,

- financed amount,

- delivery order term,

- financing procurement price,

- costs for M\&V and other performance-period services,

- escalation rates,

- guaranteed savings,

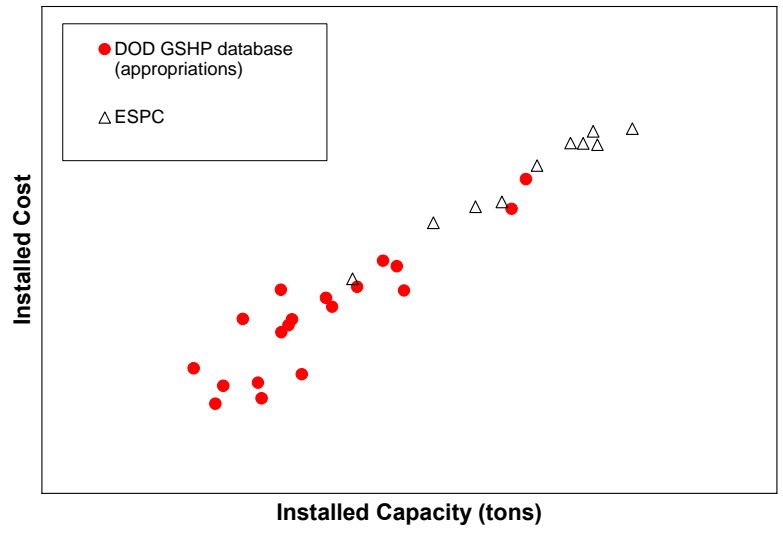

Fig. 1. Nonresidential ground-source heat pump (GSHP) cost vs. installed capacity, ECMs installed in directly funded energy projects and ESPCs.

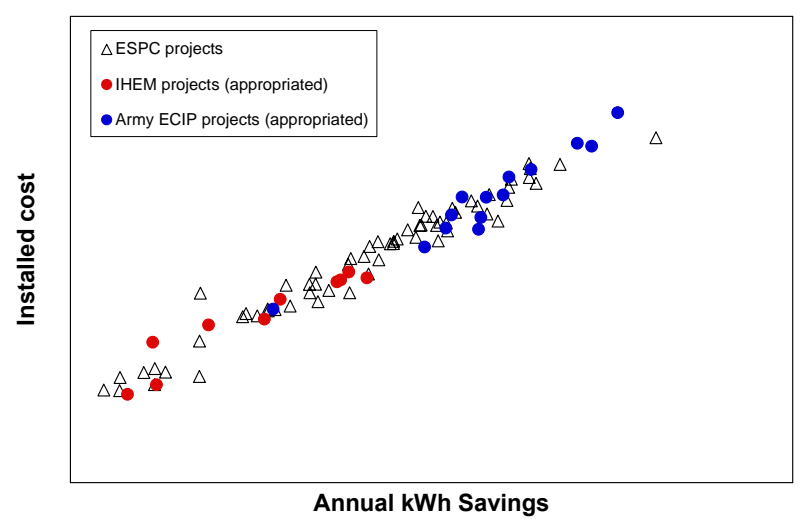

Fig. 2. Lighting ECM cost vs. annual kWh savings, ECMs installed in directly funded energy projects and ESPCs.

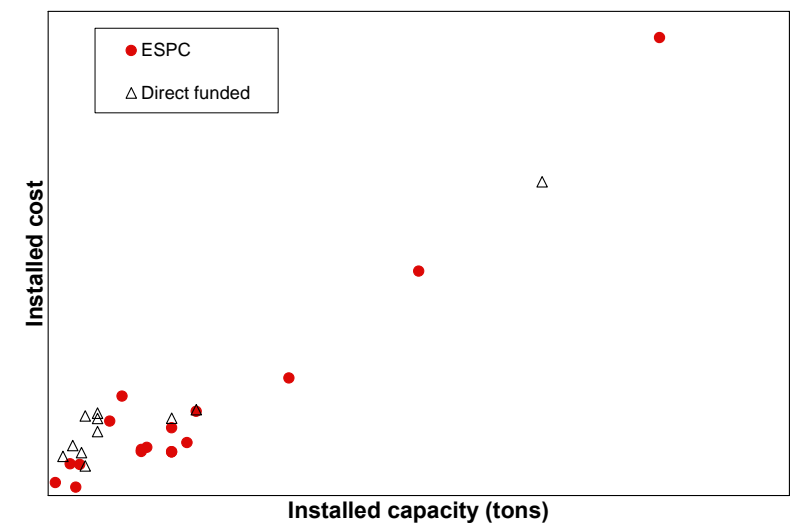

Fig. 3. Chiller replacement cost vs. capacity, ECMs installed in directly funded energy projects and ESPCs. 
- cycle time (time from kickoff meeting to award and from award to government acceptance of the operating project), and

- interest costs.

The 2002 analysis was based on data derived from program records and the financial schedules of the first 71 DOE Super ESPC delivery orders (worth \$232 million in project investment), all awarded by the end of FY 2001, which accounted for nearly one quarter of all federal ESPC investment at that time.

For the 2006 follow-up the sample consisted of all 142 Super ESPC projects awarded through July of 2006, worth $\$ 743$ million in project investment, and accounting for about $40 \%$ of all federal ESPC investment. This larger sample yields a more robust set of averages for the representative project than was available for the 2002 study.

\section{Comparing Processes}

After establishing that there is no difference in ECM pricing for ESPCs and directly funded projects, we turn to the process aspects of energy projects that determine life-cycle costs, primarily cycle time and survey and study costs.

\section{The ESPC Process}

The schedule and cycle time for the representative ESPC process is based on the averaged schedules for all awarded Super ESPC projects. The process includes the following steps:

- Kickoff meeting

- Initial proposal

- Notice of intent to award

- Detailed energy survey/30\% design

- Final proposal

- Award

- Completion of design and construction

- Government acceptance of the project and beginning of the performance period

\section{The Process for Directly Funded Projects}

The steps, timing, and costs that characterize the appropriations model are based on about $\$ 28$ million worth of projects proposed for agency funding by one federal site during FY 1994 and 1995.

The model of the appropriations-funded project is based on the two-step process used by several large agencies for distributing direct project funding to sites. Agency sites compete with each other for limited appropriation dollars for agency energy projects.

- First the site requests funds for an energy survey and feasibility study for a proposed project.

- If funding is received, the site completes a survey and study to estimate cost and benefits of the proposed project, including a detailed cost estimate based on 30\% completed design, and submits a request for implementation funding.

- Agency HQ annually selects "winners” from among all requests and allocates funding. 
- If received, the requested funding is used to complete the design and construct the project.

Some projects are submitted multiple times before they are selected for funding.

\section{Cycle Times Compared}

The time it takes for an energy project to be funded and completed and for ECMs to begin operating is a primary factor in life-cycle cost. During the delays in implementing energy projects, inefficient older equipment remains in service, wasting energy and requiring higher maintenance and repair expenditures, and therefore potential energy and cost savings are lost.

In the sample of 12 projects examined for the 2002 study, the appropriations-funded projects took about three years longer to implement than the ESPCs because of the wait for funding (see Fig. 4). A much larger sample of 93 appropriations-funded projects examined by others took almost four years longer (DOE Office of Inspector General, Report on DOE's In-House Energy Management Program, DOE/IG-0317, January 1993).

No further analysis on cycle times for directly funded projects was possible for this follow-up study because, despite an extensive search, we have not located any additional relevant data. About all that can be said based on available information is that ESPC can achieve operating projects in 28 months on average, and while individual agency experience may vary, direct funding takes considerably longer.

\section{Super ESPC process}

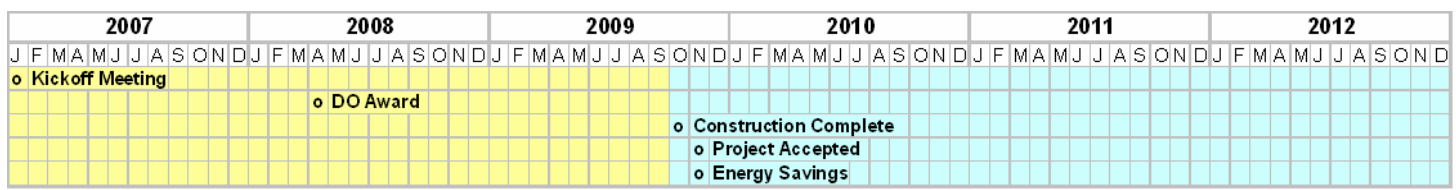

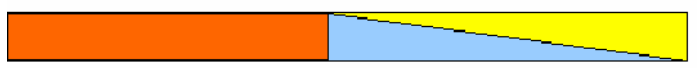

Typical appropriations process

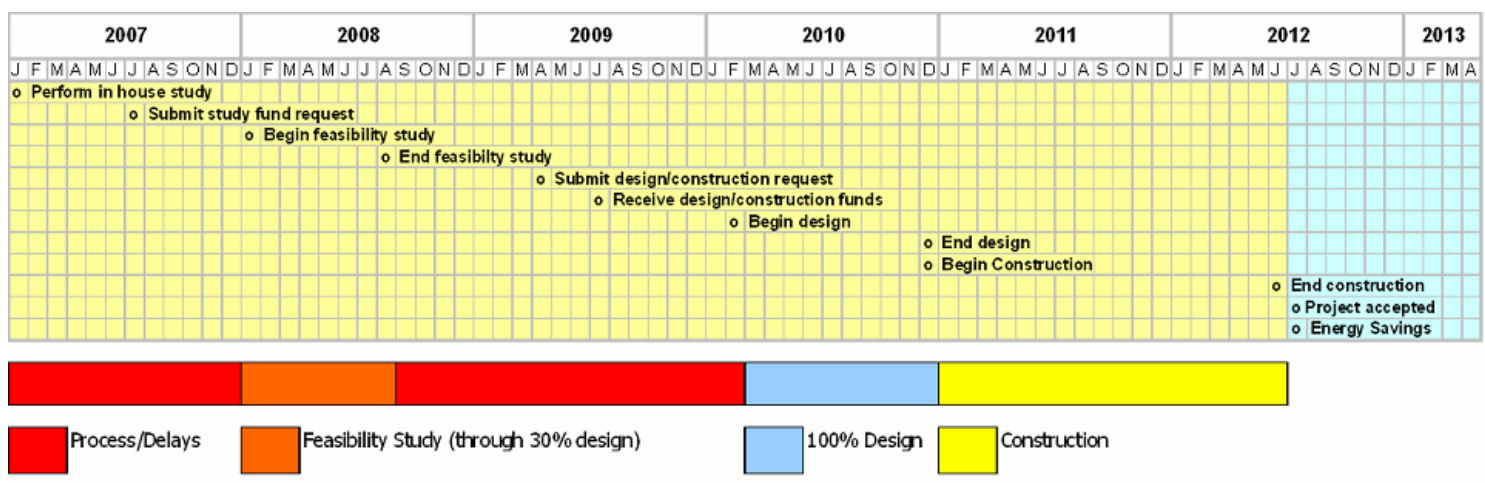

Fig. 4. In the projects studied for the 2002 study, completing the appropriations-funded process took about two years longer than completing a Super ESPC project. 


\section{Calculating Life-Cycle Costs}

All costs entailed in the representative ESPC and appropriations-funded projects (listed below) are considered in calculating the 20-year life-cycle costs of each.

\section{Costs Considered in Life-Cycle-Cost Analysis}

\section{ESPC}

- Project facilitator

- Excess energy use before equipment is installed

- Payments to ESCO (including principal, interest, and for performance-period services)

- O\&M costs after term expires

- Salvage value

\section{Appropriations}

- Excess energy use before equipment is installed

- Construction costs

- O\&M costs during equipment life

- Salvage value

\section{Survey and Study Costs}

Survey and study costs for appropriations-funded energy projects appear to vary widely. Some agencies provide funds for sites to use for the studies and surveys that must be submitted to request energy project funding, and others do not, although most programs still require estimates of costs and benefits for proposed projects and use such estimates for ranking requests.

If agencies do not provide funding for the required studies, then the sites must be funding the studies in some other way. In either case, survey and study costs must be included in energy project costs. If there is truly no cost associated with estimates of costs and benefits of proposed energy projects, then the estimates must be assumed to be of little value, and agencies managing their energy project funds by requiring sites to compete on the basis of such estimates may be accomplishing less than they hope.

Another issue is that when agencies fund only some of the proposed energy projects, the agency and/or its sites still must pay for the studies and surveys for projects that are never funded.

\section{Parametric Analysis}

To reflect the range of survey and study costs and cycle times that agencies might experience with their appropriations-funded projects, the 2002 study and this follow-up calculated the lifecycle costs for cycle times ranging from 28 to 74 months and survey and study costs ranging from 4 to $26 \%$ of project cost. Then we calculated the ratios of directly funded project life-cycle costs (for each parameterized case) to the life-cycle costs of the representative ESPC project.

Detailed results of the parametric analysis are shown in Table 1.

\section{Results of Life-Cycle-Cost Analysis - 2002}

The 2002 analysis found that the average ESPC compared favorably to directly funded projects when:

- Costs incurred for surveys and studies to obtain direct funding were more than about $10 \%$ of project construction costs,

- ESPC cycle time was faster by about two years,

- ECM prices are the same in each process, and

- Financing rates are as they were in ESPCs up until 2002 (relatively high).

These conditions were true in many of the samples that we studied. 
Table 1.

Ratios of life-cycle costs of directly funded energy projects to life-cycle costs of the representative ESPC project. Life-cycle costs and ratios are calculated for a range of survey and study costs and cycle times for directly funded projects. Values less than 1.00 (shaded cells) indicate cases of the directly funded project that have a lower life-cycle cost than the representative ESPC. Life-cycle costs calculated using post-reforms average interest rates, the current discount rate (4.6\%) and the current inflation rate (1.6\%).

Cycle time $^{a}$

Survey/study costs as percent of IP

\begin{tabular}{l|rlllllllllll} 
& $4 \%$ & $6 \%$ & $8 \%$ & $10 \%$ & $12 \%$ & $14 \%$ & $16 \%$ & $18 \%$ & $20 \%$ & $22 \%$ & $24 \%$ & $26 \%$ \\
0 & 0.93 & 0.94 & 0.95 & 0.96 & 0.98 & 0.99 & 1.00 & 1.01 & 1.03 & 1.04 & 1.05 & 1.06 \\
2 & 0.93 & 0.94 & 0.95 & 0.97 & 0.98 & 0.99 & 1.00 & 1.02 & 1.03 & 1.04 & 1.05 & 1.07 \\
4 & 0.93 & 0.95 & 0.96 & 0.97 & 0.98 & 1.00 & 1.01 & 1.02 & 1.03 & 1.05 & 1.06 & 1.07 \\
6 & 0.94 & 0.95 & 0.96 & 0.98 & 0.99 & 1.00 & 1.01 & 1.03 & 1.04 & 1.05 & 1.06 & 1.08 \\
8 & 0.94 & 0.96 & 0.97 & 0.98 & 0.99 & 1.01 & 1.02 & 1.03 & 1.04 & 1.06 & 1.07 & 1.08 \\
10 & 0.95 & 0.96 & 0.97 & 0.99 & 1.00 & 1.01 & 1.02 & 1.03 & 1.05 & 1.06 & 1.07 & 1.08 \\
12 & 0.95 & 0.96 & 0.98 & 0.99 & 1.00 & 1.01 & 1.03 & 1.04 & 1.05 & 1.06 & 1.08 & 1.09 \\
14 & 0.96 & 0.97 & 0.98 & 0.99 & 1.01 & 1.02 & 1.03 & 1.04 & 1.06 & 1.07 & 1.08 & 1.09 \\
16 & 0.96 & 0.97 & 0.99 & 1.00 & 1.01 & 1.02 & 1.04 & 1.05 & 1.06 & 1.07 & 1.08 & 1.10 \\
18 & 0.97 & 0.98 & 0.99 & 1.00 & 1.01 & 1.03 & 1.04 & 1.05 & 1.06 & 1.08 & 1.09 & 1.10 \\
20 & 0.97 & 0.98 & 0.99 & 1.01 & 1.02 & 1.03 & 1.04 & 1.06 & 1.07 & 1.08 & 1.09 & 1.10 \\
22 & 0.97 & 0.99 & 1.00 & 1.01 & 1.02 & 1.04 & 1.05 & 1.06 & 1.07 & 1.08 & 1.10 & 1.11 \\
24 & 0.98 & 0.99 & 1.00 & 1.01 & 1.03 & 1.04 & 1.05 & 1.06 & 1.08 & 1.09 & 1.10 & 1.11 \\
26 & 0.98 & 0.99 & 1.01 & 1.02 & 1.03 & 1.04 & 1.06 & 1.07 & 1.08 & 1.09 & 1.10 & 1.12 \\
28 & 0.99 & 1.00 & 1.01 & 1.02 & 1.03 & 1.05 & 1.06 & 1.07 & 1.08 & 1.10 & 1.11 & 1.12 \\
30 & 0.99 & 1.00 & 1.01 & 1.03 & 1.04 & 1.05 & 1.06 & 1.08 & 1.09 & 1.10 & 1.11 & 1.12 \\
32 & 0.99 & 1.01 & 1.02 & 1.03 & 1.04 & 1.06 & 1.07 & 1.08 & 1.09 & 1.10 & 1.12 & 1.13 \\
34 & 1.00 & 1.01 & 1.02 & 1.03 & 1.05 & 1.06 & 1.07 & 1.08 & 1.09 & 1.11 & 1.12 & 1.13 \\
36 & 1.00 & 1.01 & 1.02 & 1.04 & 1.05 & 1.06 & 1.07 & 1.09 & 1.10 & 1.11 & 1.12 & 1.13 \\
38 & 1.00 & 1.02 & 1.03 & 1.04 & 1.05 & 1.07 & 1.08 & 1.09 & 1.10 & 1.11 & 1.13 & 1.14 \\
40 & 1.01 & 1.02 & 1.03 & 1.04 & 1.06 & 1.07 & 1.08 & 1.09 & 1.11 & 1.12 & 1.13 & 1.14 \\
42 & 1.01 & 1.02 & 1.04 & 1.05 & 1.06 & 1.07 & 1.08 & 1.10 & 1.11 & 1.12 & 1.13 & 1.15 \\
44 & 1.02 & 1.03 & 1.04 & 1.05 & 1.06 & 1.08 & 1.09 & 1.10 & 1.11 & 1.12 & 1.14 & 1.15 \\
46 & 1.02 & 1.03 & 1.04 & 1.06 & 1.07 & 1.08 & 1.09 & 1.10 & 1.12 & 1.13 & 1.14 & 1.15 \\
$a$
\end{tabular}

${ }^{a}$ Months in addition to average cycle time of Super ESPCs.

\section{Results of Life-Cycle-Cost Analysis - 2006}

The 2006 analysis found that improved financing for ESPCs improves their comparative value. The follow-up study shows that the average ESPC, with post-2004 financing, compared favorably to directly funded projects when:

- Costs incurred for surveys and studies to obtain direct funding were more than about $6 \%$ of project construction costs,

- ESPC cycle time was faster by about two years than cycle time for directly funded projects, and

- $\quad$ ECM prices are the same. 


\section{Impact of Lower ESPC Interest Rates}

For the 2006 follow-up, instead of using the average interest rates for all Super ESPC awards (as we did for the original study), we used the average of rates from the awards after 2004 only. The data collected continuously on Super ESPC projects indicates that Super ESPC projects have changed significantly since the new requirements for competition and transparency in financing were incorporated into the Super ESPC contracts in 2004.

The total interest rate for Super ESPC projects includes the index interest rate (which depends on the financial markets and cannot be controlled) and the premium, which is set by the lender. The premiums in the financing on Super ESPCs have dropped by about $50 \%$ since the financing reforms took effect, lowering overall costs considerably.

Better financing has been followed by changes in the structure of Super ESPC projects. Lower interest rates reduce costs, and agencies have the flexibility to realize these cost savings in several different ways in their ESPCs. They can

- reduce the contract term,

- fund additional, longer-payback ECMs, or

- fund additional performance-period services.

Lower interest rates have reduced the total payments over contract term for an average Super ESPC project by $16 \%$.

\section{Sensitivity to Discount Rate}

The results of the LCC comparison shown in Table 1 are sensitive to the discount rate used in the calculations. Higher discount rates make future payments look better in comparison with up-front payments, and so make ESPCs look better compared to direct funding.

The official discount rate published by NIST/EIA is presently quite low, at $4.6 \%$, and is likely to rise when adjusted next, in April 2007. The discount rate was 6.1\% at the time of the original study. This follow-on study uses today's lower discount rate, but even so, ESPCs compare more favorably to direct funding than in the original study because ESPC interest rates have improved by a wide margin.

\section{Persistence of Savings}

The results of the 2006 analyses reviewed above assume that persistence of savings is the same in directly funded projects as it is in ESPCs. Savings guarantees and required annual M\&V ensure that savings do persist in ESPC projects, but such assurances are rare in directly funded projects. 
Even a small degradation in savings of $0.5 \%$ per year (10\% over 20 years) makes ESPCs more life-cycle cost-effective under most realistic circumstances.

\section{Conclusions}

The primary factors in comparing life-cycle costs of directly funded projects and ESPCs are

- how much it costs sites to develop funding requests and

- how long it takes agencies to deliver appropriated funds to sites.

Given the average of all awarded Super ESPC projects, along with post-reform financing, ESPCs have a lower life-cycle cost whenever directly funded projects take more than two years longer than ESPCs to complete and survey and study costs are greater than $6 \%$ of project cost.

Calculations of compared life-cycle costs are sensitive to the discount rate used in figuring net present value, but higher discount rates improve the comparative value of ESPCs. Since the discount rate is relatively low at this writing, the two-year and 6\% break-even metric stated above is likely conservative.

The 2002 study found that there is no statistically significant difference in the pricing of ECMs for directly funded vs. ESPC projects. After the 2006 follow-up, we still see no evidence of any difference in ECM pricing.

Financing reforms implemented through 2004 modifications to the Super ESPC contracts have lowered interest rate premiums by about $50 \%$ compared to pre-reform project interest rates. Because of better interest rates, agencies pay about 16\% less for the average ESPC project over the term of the contract. 